\title{
CONTRIBUIÇÃO AO MANEJO SUSTENTÁVEL DO COMPLEXO FERRUGINOSO NECTANDRA NA FLORESTA NACIONAL DE IBIRAMA, SC ${ }^{1}$
}

\author{
Fernando Campanhã Bechara ${ }^{2}$, Erasmo Nei Tiepo $^{3}$ e Ademir Reis ${ }^{4}$
}

\begin{abstract}
RESUMO - Diante do mercado aberto para a produção de madeiras tropicais, o complexo ferruginoso Nectandra (CFN), formado pelo grupo de espécies Nectandra lanceolata, N. oppositifolia e N. rigida (canelas-ferrugem), possui aspectos promissores, pois apresenta madeira de alto valor mercadológico e com potencial silvicultural. Esse grupo de espécies é de difícil distinção em campo, justificando-se o manejo do complexo em conjunto. Essas são as primeiras espécies madeireiras a se tornarem abundantes em florestas secundárias na Região Sul do país, favorecidas pela abertura de pequenas clareiras. Realizaram-se estudos demográficos desse grupo, na FLONA de Ibirama, SC, objetivando alicerçar o manejo sustentável de madeira para serraria. Numa Floresta Ombrófila Densa de 38 ha, foram inventariados todos os indivíduos do CFN presentes em 14 parcelas aleatórias de 40 × $40 \mathrm{~m}$. Caracterizou-se a distribuição espacial das árvores, bem como a produção de madeira. A população apresentou distribuição espacial aleatória, sendo $58 \%$ de toras de boa qualidade. Ocorreram 43 indivíduos/ ha na regeneração, o que caracteriza a formação de banco de plântulas. Foi possível explorar 11 árvores/ ha $\left(\right.$ com DAP $>16 \mathrm{~cm}$ ), o que representaria $3,5 \mathrm{~m}^{3}$ de madeira/ha. Um ciclo de corte de 20 anos renderia quase $7 \mathrm{~m}^{3}$ de madeira de alta qualidade ao ano. Dez por cento das árvores adultas apresentaram três rebrotas/ indivíduo, estabelecendo o potencial de segunda rotação. As árvores classificadas como toras de "baixa qualidade" (32\% do total) e com DAP > $40 \mathrm{~cm}$ podem ser deixadas como porta-sementes. Recomendam-se estudos mais detalhados de demografias espacial e temporal, autoecologia e análise econômica para alicerçar o manejo sustentável.
\end{abstract}

Palavras-chave: Manejo florestal, Lauraceae e madeiras tropicais.

\section{CONTRIBUTION TO SUSTAINABLE FOREST MANAGEMENT OF THE NECTANDRA FERRUGINOUS COMPLEX IN THE IBIRAMA NATIONAL FOREST, SC, BRAZIL}

\begin{abstract}
In view of the opening of the tropical wood production market, the Nectandra ferruginous complex (NFC), defined as a group of Nectandra species - N. lanceolata, N. oppositifolia and N. rigida-offers promising prospects, because of its high mercantile value wood and silvicultural potential. The Nectandra species complex is not easily identified, what justifies its management as a whole. They are the first wood species to become abundant in secondary forests in southern Brazil, favored by the opening of small gaps. Demographic studies of this group were carried out in the Ibirama National Forest, to build a foundation for the sustainable management for sawmill wood. In a 38 ha forest, all individuals of the NFC were analyzed in 14 random plots of $40 x$ $40 \mathrm{~m}$. The spatial distribution of the trees was characterized as well as the sampling and log quality and wood production. The population displayed randomized space distribution and $58 \%$ good quality logs. During regeneration, 43 plants/ha were counted, characterizing formation of a seedling bank. Eleven trees/ha (with $D B H>16 \mathrm{~cm}$ ) can be exploited, representing $3.5 \mathrm{~m}^{3}$ of wood/ha. A 20-year old cut cycle would relieve 7
\end{abstract}

\footnotetext{
${ }^{1}$ Recebido em 20.01.2007 e aceito para publicação em 26.01.2009.

${ }^{2}$ Coordenação de Engenharia Florestal da Universidade Tecnológica Federal do Paraná (UTFPR). E-mail: <bechara@ utfpr.edu.br>.

${ }^{3}$ Programa de Pós-Graduação em Biologia Vegetal da Universidade Federal de Santa Catarina (UFSC).

${ }^{4}$ Departamento de Botânica da UFSC. E-mail: <areis@ @ccb.ufsc.br>.
} 


\begin{abstract}
$m^{3}$ of high quality wood per year. Ten percent of the adult trees presented 3 sprouts per individual indicating potential for a second rotation management. Trees classified as logs of "low quality" (32\% of the total) and with DBH > $40 \mathrm{~cm}$ can be left as seed-trees. Plant monitoring, auto-ecology studies, and economic analysis are needed to underpin a sustainable management.
\end{abstract}

Keywords: Forest management, Lauraceae and tropical woods.

\section{INTRODUÇÃO}

Desde o período colonial e a chegada dos imigrantes europeus, as madeiras de espécies nativas da Floresta Atlântica foram intensamente exploradas de maneira extrativista e predatória (REITZ et al., 1978; KLEIN etal., 1986; REIS, 1995; VERISSIMO et al., 1996; CASTRO, 2002). O modelo madeireiro de extrativismos destrutivo e clandestino, apesar de apresentar menores custos econômicos iniciais, acarreta o rápido esgotamento do estoque natural de madeira a altos custos socioambientais (VERISSIMO et al., 1996). Todavia, a garantia de produção contínua de madeira, associada à conservação de biodiversidade, pode ser alcançada mediante o manejo florestal sustentável. A finalidade do manejo em regime sustentável é conseguir que as florestas nativas forneçam continuamente benefícios econômicos, ecológicos e sociais, mediante um planejamento para o aproveitamento dos recursos madeireiros e não-madeireiros disponíveis (REIS et al., 2000; GAMA et al., 2005).

O pequeno número de espécies madeiráveis nas florestas tropicais da América do Sul sempre foi apontado como fator limitante para a implantação do manejo sustentável, tornando-se um agravante para os efeitos deletérios do extrativismo predatório (ANGELO e GUIMARÃES, 2001). Há previsões de que, nos próximos anos, o estoque de madeiras tropicais destinados para serraria na Região Amazônica entre em declínio em razão da exploração concentrada em poucas espécies, da falta de infra-estrutura e, principalmente, da baixa qualidade da madeira produzida devido ao insatisfatório nível tecnológico. Isso resulta em grande desperdício, e apenas $30 \%$ de uma tora é aproveitada, ou seja, $70 \%$ vira lixo urbano e rural no ato de processamento. Dessa maneira, surge um consistente mercado futuro voltado para a produção de madeiras tropicais de alta qualidade, especializado em exportação para países como Japão, Europa e Estados Unidos (CLEMENT e HIGUCHI, 2006).
O grupo de espécies arbóreas do gênero Nectandra Rol. ex Rottb. (Lauraceae) com ramos e folhas de coloração ferruginosa (canela-ferrugem, canela-amarela) possui taxonomia complexa, o que resultou numa polêmica entre especialistas botânicos quanto à separação de seus táxons (PEDRALLI, 1987; ROHWER, 1992, 1993; PEDRALLI, 1996). Devido a esse conflito taxonômico, neste trabalho tais espécies foram agrupadas no aqui denominado "Complexo Ferruginoso Nectandra" (CFN), composto pelas seguintes espécies: Nectandra lanceolata Nees, Nectandra oppositifolia Nees \& Mart. e Nectandra rigida (Kunth) Nees. Em virtude da dificuldade de distinção inequívoca entre essas espécies por taxonomistas e da inviabilidade de separação específica de seus indivíduos em campo (especialmente árvores altas, sem material reprodutivo), a formação do CFN, além de tornar o manejo exequível, permite a exploração de até três espécies de modo conjunto, o que diminui a pressão sobre uma espécie isolada.

As espécies do CFN são as primeiras espécies com potencial madeireiro a se tornarem abundantes em florestas secundárias em estágio avançado de sucessão, atingindo até $25 \mathrm{~m}$ de altura (REITZ et al., 1983). Possuem rápido crescimento monopodial e formam fustes de alto interesse comercial, especialmente com a abertura de pequenas clareiras de luz difusa (REITZ et al., 1983; CARVALHO, 1994). Nesse sentido, o CFN possui grande potencial em projetos de manejo e enriquecimento de florestas secundárias. Além disso, com distribuição ampla (desde a Amazônia até o Rio Grande do Sul), esse grupo de espécies está entre as arbóreas mais frequentes na Região Sul do país, e sua alta plasticidade ambiental lhe confere presença nas mais diversas fitofisionomias (REITZ et al., 1983; PEDRALLI, 1987).

Este trabalho teve como objetivo apresentar estudos demográficos básicos, a fim de alicerçar o manejo florestal sustentável do CFN, visando à utilização da madeira 
para laminação na Floresta Nacional (FLONA) de Ibirama, SC. Segundo o Art. 17 do Sistema Nacional de Unidades de Conservação/Lei 9.985, a categoria FLONA "tem como objetivo básico o uso múltiplo sustentável dos recursos florestais e a pesquisa científica, com ênfase em métodos para exploração sustentável de florestas nativas" (BRASIL, 2000, p. 16), enfatizando o escopo deste trabalho e a vocação da área de estudo.

\section{MATERIAL E MÉTODOS}

\subsection{Descrição da madeira do complexo ferruginoso Nectandra (CFN)}

As espécies do CFN possuem madeira de características muito semelhantes, como ocorre geralmente em lauráceas (MUNIZ e MARCHIORI, 1999). Apesar de pouco difundidas pelo marketing do setor madeireiro (ANGELO e GUIMARÃES, 2001), tais espécies possuem madeira de alto valor econômico já comprovado, estando entre as 11 espécies madeireiras com maior potencial no país (CARVALHO, 1994). Sua madeira é moderadamente pesada (massa específica básica de $0,48 \mathrm{~g} / \mathrm{cm}^{3}$ ), de coloração amarela e brilhante e de boa trabalhabilidade (REITZ et al., 1983; CARVALHO, 1994; MUNIZ e MARCHIORI, 1999). Seu uso é indicado para caixotaria, postes, moirões, construção civil (vigas, caibros, ripas, sarrafos, tacos, esquadrias e forros) e, especialmente, movelaria nobre (PEDRALLI, 1987). Muniz e Marchiori (1999) salientaram que a madeira dessas espécies não apresenta cristais, sendo propícia para a fabricação de chapas e compensados ornamentais.

\subsection{Caracterização da área de estudo}

Este trabalho foi desenvolvido na Floresta Nacional (FLONA) de Ibirama. Criada em 1988, essa FLONA perfaz uma área de 570,58 ha e situa-se na porção nordeste do Estado de Santa Catarina, entre as latitudes $27^{\circ}$ $00 ' 51^{\prime \prime} \mathrm{S}$ a $27^{\circ} 02$ ' $28^{\prime}$ ' $\mathrm{S}$ e as longitudes $49^{\circ} 26^{\prime} 59^{\prime}$ ' W a $49^{\circ} 28^{\prime} 08^{\prime \prime} \mathrm{W}$, abrangendo parte dos Municípios de Ibirama, Apiuna e Ascurra. De acordo com a classificação de Köppen, o clima regional é do tipo Cfa-mesotérmico úmido com verão quente, apresentando temperatura média anual de $18-20^{\circ} \mathrm{C}$, temperatura média do mês mais quente (janeiro) de $22-26^{\circ} \mathrm{C}$ e temperatura média do mês mais frio (julho) de $12-16^{\circ} \mathrm{C}$. A precipitação total anual é de 1.600-1.800 mm, com excedente hídrico de 600-800 mm. A umidade relativa anual é de 75-80\%
(SANTACATARINA, 1986). A região possui cambissolo álico e é cortada em sua parte mais baixa pelo ribeirão do Coxo, um afluente do rio Itajaí-Açu, além de possuir nascentes de vários outros afluentes deste último (SALAZAR FILHO et al., 2008).

A maior parte da vegetação (80\%) da FLONA de Ibirama é composta por Floresta Ombrófila Densa (463 ha), onde a cobertura varia de floresta primária a secundária em estágio intermediário de regeneração. O uso do solo da FLONA ainda é composto por 8 ha de reflorestamentos de Araucaria angustifolia (Bertol.) Kuntze, 8 ha de Eucalyptus e 14 ha de Pinus, sendo o restante constituído por pastagens e área construída (SALAZAR FILHO et al., 2008). Além do CFN, há outras espécies madeiráveis valiosas, ocorrentes na área de estudo, as quais também são favorecidas por pequenas clareiras antrópicas, como Cedrela fissilis Vell. (cedro) e Cabralea canjerana (Vell.) Mart. (canjarana) (KLEIN, 1984; MACEDO et al., 1993; DURIGAN et al., 1997; BOLIGONI et al., 2005).

\subsection{Amostragem e Coleta de Dados}

Numa área contínua de Floresta Ombrófila Densa de 38 ha, foi realizado um inventário florestal de todos os indivíduos do CFN presentes em 14 parcelas aleatórias de 40 x 40 m, totalizando 2,24 ha de área amostral. Cada parcela foi subdividida em 16 unidades amostrais de 10 x $10 \mathrm{~m}$. Foi avaliado o diâmetro à altura do peito (DAP) do caule principal de todos os indivíduos adultos, que foram considerados como aqueles com altura superior a 1,3 m. A altura comercial (comprimento do fuste até a primeira ramificação de copa) dos indivíduos adultos foi estimada com o auxílio de régua dendrométrica de $12 \mathrm{~m}$. Consideraram-se $16 \mathrm{~cm}$ como o DAP mínimo de corte para laminação. Foi avaliada a qualidade das toras e registrado o número de rebrotas maiores do que 1,3 $\mathrm{m}$ de altura por árvore. Também, foi mensurada a altura de todas as plantas inferiores a 1,3 m, consideradas indivíduos juvenis.

Realizou-se a caracterização da distribuição espacial das árvores com DAP superior a $40 \mathrm{~cm}$, nas parcelas de 40 x 40 m, calculando-se o índice de dispersão de Morisita (1954), IM $=\mathrm{n}\left[\left(\Sigma \mathrm{x}^{2}-\mathrm{N}\right) / \mathrm{N}(\mathrm{N}-1)\right]$, em que $\mathrm{n}=\mathrm{n}^{\circ}$ de parcelas; $\mathrm{N}=\mathrm{n}^{\circ}$ de plantas amostradas; e $\Sigma \mathrm{x}^{2}=$ somatório do quadrado do número de árvores presentes por parcela.

R. Árvore, Viçosa-MG, v.33, n.1, p.125-132, 2009 


\subsection{Análise dos dados}

As distribuições diamétrica e hipsométrica da população, bem como a presença de rebrotas nas árvores adultas, foram avaliadas. Calculou-se o volume cilíndrico, segundo Heinsdijk e Bastos (1963): Vol $\left(\mathrm{m}^{3}\right)=((\pi / 40000)$ $\left.\mathrm{x} \mathrm{DAP}^{2}\right) \mathrm{x}$ altura comercial. Optou-se em estimar o volume seguindo níveis distintos de fator de forma (FF), para cada classe de qualidade de tora, em que: Classe I: $\mathrm{FF}=0,5$; Classe II: $\mathrm{FF}=0,4$; e Classe III: $\mathrm{FF}=0,3$. A precisão da amostragem foi obtida através do cálculo do erro amostral e intervalo de confiança das médias obtidas, com $95 \%$ de probabilidade, pelo teste t. Para tanto, considerou-se um erro máximo de $10 \%$.

As toras, com DAP superior a $16 \mathrm{~cm}$, foram agrupadas em três classes de qualidade: Classe I: fuste reto e cilíndrico; Classe II: tortuosidade moderada e moderadamente cilíndrica; e Classe III: tortuosa e não cilíndrica, com sinais de madeira decomposta, predadores ou parte interna oca.

Para a interpretação do índice de Morisita (IM), considerou-se que: $1<$ IM < 2, distribuição aleatória; IM > 2, distribuição agrupada; e IM < 1, distribuição regular (KREBS, 1989).

\section{RESULTADOS E DISCUSSÃO}

Registrou-se um total de 23 indivíduos adultos do complexo ferruginoso Nectandra $(\mathrm{CFN})$ por hectare, estando $49 \%$ destes com DAP acima de $16 \mathrm{~cm}$. Tais árvores, consideradas exploráveis, ocorreram com alta frequência absoluta em $64 \%$ das parcelas, denotandose sua ampla distribuição por quase toda a extensão da área de estudo, possivelmente por apresentarem baixa especificidade por sítios com características edáficas peculiares (PEDRALLI, 1987). Nesse sentido, o valor do índice de Morisita (1,33) indica que a população amostrada do CFN possui padrão de distribuição aleatório no campo, corroborando com os resultados obtidos da análise fitossociológica. Provavelmente, esse padrão de dispersão pode estar relacionado à formação eventual de clareiras das florestas tropicais. Segundo Reitz et al. (1983), as espécies do CFN se beneficiam da entrada de luminosidade proporcionada por pequenas clareiras, fator que provavelmente aceleraria ainda mais a produção de madeira de segundo ciclo.

Foi observado um padrão de rebrotação nos indivíduos adultos do CFN, e 62,5\% das árvores com rebrotas se encontravam inclinadas (Figura 1). As árvores com rebrotas apresentaram DAP médio de 34 cm (desvio- padrão de $11 \mathrm{~cm}$ ). Foram registrados cinco indivíduos adultos com rebrotas/ha, isto é, $10 \%$ dos indivíduos adultos da população amostrada. Desses, houve em média três rebrotas por indivíduo (desvio-padrão de um indivíduo). Em estudo de desempenho silvicultural, Carvalho (1994) também verificou rebrotação nas espécies do CFN. Portanto, existe alto potencial para o manejo de segunda rotação do CFN, no qual se poderia eliminar rebrotas de menor qualidade em privilégio de uma única rebrota mais bem desenvolvida. Tal manejo seria interessante, pois, além de preservar a diversidade genética dos indivíduos originais, as rebrotas de lauráceas de grande porte, geralmente, apresentam crescimento acelerado, devido ao aproveitamento do volume radicular originário do indivíduo adulto (HERING, 1994).

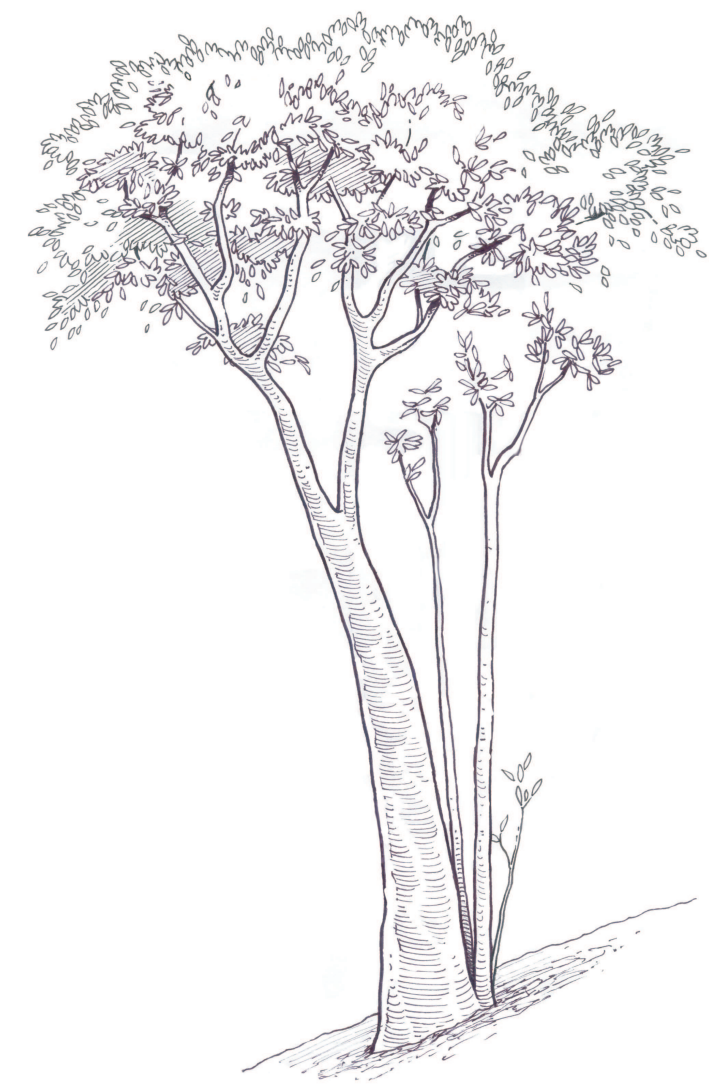

Figura 1 - Padrão de propagação vegetativa observado em indivíduos adultos do complexo ferruginoso Nectandra: fuste principal inclinado e rebrotas vigorosas com potencial de manejo de segunda rotação.

Figure 1 - Observed patterns of vegetative propagation of adult individuals of Nectandra ferruginous complex: inclined main trunk and vigorous sprouts with potential of second rotation management. 
A distribuição diamétrica das árvores do CFN consideradas adultas apresentou a primeira classe de DAP $(0-8 \mathrm{~cm})$ com três indivíduos/ha, representados por árvores jovens e estioladas que poderão abastecer as classes diamétricas seguintes, após o primeiro ciclo de corte (Figura 2). Porém, a primeira classe de DAP constitui um "gargalo" para o regime de manejo sustentável, já que o grande aumento no número de indivíduos da primeira para a segunda classe (tendo esta mais que o dobro de indivíduos) representa uma carência de provimento de indivíduos para a segunda classe diamétrica $(8-16 \mathrm{~cm})$. A reduzida quantidade de indivíduos na primeira classe, provavelmente, ocorreu em razão de alta mortalidade de arvoretas. Essa classe deve ser bem focada em intervenções de manejo, a fim de se eliminarem possíveis competidores e reduzir a mortalidade de seus indivíduos, procurando, desse modo, abastecer a classe seguinte e, consequentemente, a terceira classe diamétrica e as classes subsequentes. Isso pode ser obtido através de plantio e manutenção de mudas, condução de arvoretas e rebrotações de segunda rotação ou, possivelmente, provocando pequenas frestas no dossel florestal.

Associada à primeira classe de DAP, a segunda classe representa a fase de crescimento da população, com indivíduos pré-exploráveis. Estes poderão desenvolver-se quando as condições da floresta proporcionarem melhores condições de fatores ambientais de crescimento, como a entrada de luz decorrente da abertura de pequenas clareiras.

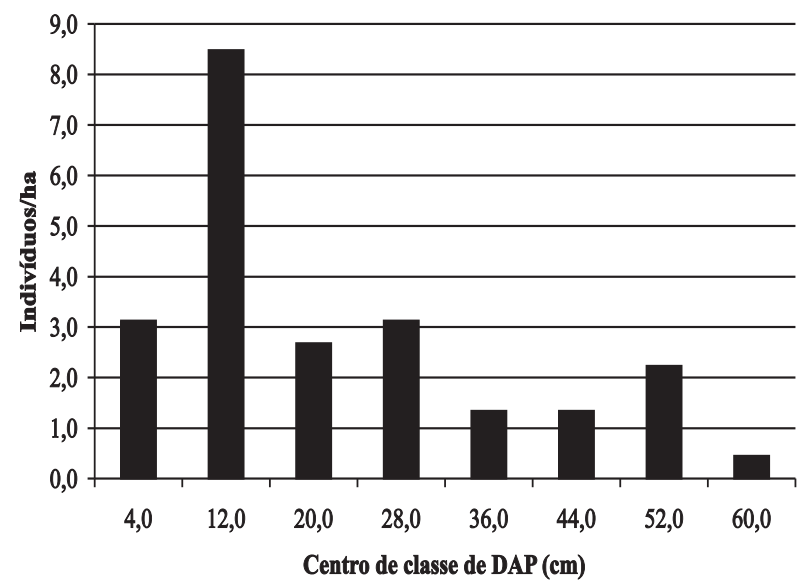

Figura 2-Classes diamétricas de população do complexo ferruginoso Nectandra na Floresta Nacional de Ibirama, SC.

Figure 2-Diametric classes of population of Nectandra ferruginous complex at Ibirama National Forest, SC, Brazil.
Da segunda para a terceira classe diamétrica ocorreu brusca diminuição no número de indivíduos, remanescendo a terceira classe com quase o mesmo número de indivíduos do que a primeira. Essa queda pode ser considerada natural, isto é, em um ambiente onde a competição não é controlada, é normal que tal estrangulamento populacional aconteça.

As três classes diamétricas subsequentes, de 24 a $40 \mathrm{~cm}$ de DAP, constituem as árvores do CFN potencialmente exploráveis, e as três últimas classes podem ser deixadas como remanescentes para atuarem como matrizes (porta-sementes). Dessa maneira, poderse-ia manter a estrutura populacional original, tanto no sentido horizontal quanto no vertical (ANJOS et al., 1998).

Foi estimada uma densidade de 43 indivíduos juvenis do CFN por hectare. A distribuição de alturas dos indivíduos jovens da população amostrada se aproximou de uma curva exponencial negativa ("J" invertido), apresentando concentração da regeneração nas duas primeiras classes, com plantas de até 1 $m$ de altura (Figura 3), caracterizando a formação de banco de plântulas sob o dossel. Tal aspecto facilitaria o manejo com o abastecimento de indivíduos para o segundo ciclo.

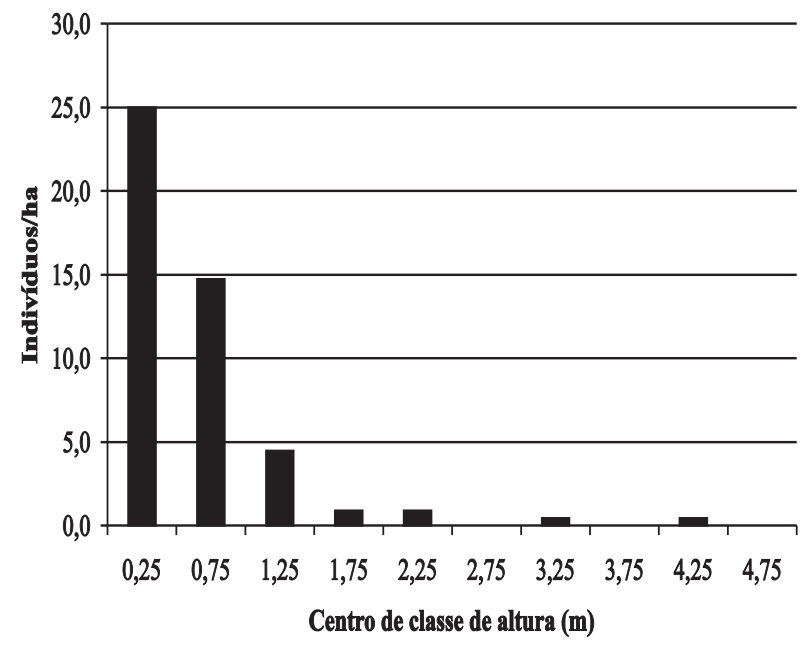

Figura 3 - Classes de altura de indivíduos jovens com até $5 \mathrm{~m}$ de altura. População do complexo ferruginoso Nectandra na Floresta Nacional de Ibirama, SC.

Figure 3 -Classes of young individuals up to $5 \mathrm{~m}$ hight. Population of Nectandra ferruginous complex at Ibirama National Forest, SC, Brazil.

R. Árvore, Viçosa-MG, v.33, n.1, p.125-132, 2009 
Os indivíduos adultos com mais de $5 \mathrm{~m}$ de altura se mostraram bem distribuídos nas classes de altura, exceto nas duas primeiras classes onde não ocorrem indivíduos, constituindo outro "gargalo" para o manejo (Figura 4). A carência dessas classes também poderia ser suprida com o manejo de rebrotas de segunda rotação. No entanto, destacou-se a classe de indivíduos de $12 \mathrm{~m}$ de altura, em virtude de poder municiar as classes subsequentes após a primeira rotação.

Na Tabela 1, apresenta-se a porcentagem de toras em cada classe, e ocorre quantidade razoável de toras de qualidades alta e moderada (classes I e II), somando $68 \%$ de toras de qualidade satisfatória. As árvores da classe III, classificadas como toras de "baixa qualidade" ( $32 \%$ do total), com DAP superior a $40 \mathrm{~cm}$, poderiam ser deixadas como porta-sementes ou, também, manejadas para condução de suas rebrotas para o segundo ciclo de corte. $\mathrm{O}$ volume de madeira do total de árvores exploráveis calculado é apresentado na Tabela 2.

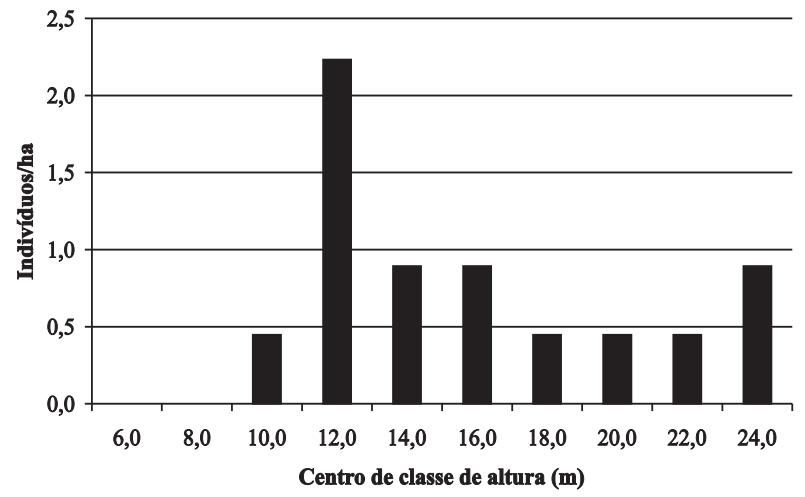

Figura 4-Classes de altura comercial de população do complexo ferruginoso Nectandra na Floresta Nacional de Ibirama, SC.

Figure 4-Commercial height classes of population of Nectandra ferruginous complex at Ibirama National Forest, SC, Brazil.

Quadro 1 - Porcentagem de toras em cada classe de qualidade. População do complexo ferruginoso Nectandra $($ DAP médio $=34 \mathrm{~cm}$; desvio-padrão $=11 \mathrm{~cm})$ na Floresta Nacional de Ibirama, SC

Table 1 - Log percentage in each quality class. Population of Nectandra ferruginous complex $(\mathrm{DBH}=34$ $\mathrm{cm}$; standard deviation $=11 \mathrm{~cm}$ ) at Ibirama National Forest, SC, Brazil

\begin{tabular}{ccc}
\hline Classe & $\begin{array}{c}\text { Qualidade } \\
\text { de Tora }\end{array}$ & $\begin{array}{c}\text { Porcentagem } \\
\text { de Toras }(\%)\end{array}$ \\
\hline I & alta & 32,0 \\
II & moderada & 36,0 \\
III & baixa & 32,0 \\
\hline
\end{tabular}

Tabela 2 - Densidade e volume de madeira da população do complexo ferruginoso Nectandra, com DAP superior a $16 \mathrm{~cm}$, na Floresta Nacional de Ibirama, SC

Table 2 -Density and wood volume of the population of Nectandra ferruginous complex with DBH higher than $16 \mathrm{~cm}$ at Ibirama National Forest, SC, Brazil

\begin{tabular}{lc}
\hline Variável & Média (Intervalode Confiança)* \\
\hline $\begin{array}{l}\text { Número de } \\
\text { indivíduos/ha }\end{array}$ & $11,2500$ (entre 9,8541 e 12,4673$)$ \\
$\begin{array}{l}\text { Volume }\left(\mathrm{m}^{3}\right) \\
\text { lárvore }\end{array}$ & $0,3165$ (entre 0,3122 e 0,3208$)$ \\
$\begin{array}{l}\text { Volume estimado } \\
\left(\mathrm{m}^{3}\right) / \text { ha }\end{array}$ & $3,5327$ (entre 3,4846 e 3,5808$)$ \\
$\begin{array}{l}\text { Volume estimado } \\
\left(\mathrm{m}^{3}\right) / 38 \text { ha }\end{array}$ & 134,2413 (entre 132,4130 e \\
\end{tabular}

$* p=0,05$.

Considerando um DAP mínimo de corte (DMC) de $16 \mathrm{~cm}$ e a exploração de $40 \%$ dos indivíduos desse porte, seria possível explorar cinco árvores do CFN por hectare. Essa intensidade de corte renderia, aproximadamente, $1,4244 \mathrm{~m}^{3}$ de madeira/ha (intervalo de confiança entre 1,4050 e $1,4438 \mathrm{~m}^{3} / \mathrm{ha}$, com $95 \%$ de probabilidade). Se se tomasse o ciclo de corte sob manejo de 20 anos, idade em que as lauráceas já poderiam apresentar DMC (TONINI et al., 2003), dividindo a área total em 20 partes, uma explorada por ano, pode-se explorar 1,9 ha ao ano. Essa intensidade de corte renderia $6,7121 \mathrm{~m}^{3}$ de madeira de alta qualidade ao ano (intervalo de confiança entre 6,6207 e $6,8035 \mathrm{~m}^{3}$, com $95 \%$ de probabilidade), o que poderia gerar boa lucratividade a pequenos e grandes proprietários rurais.

Finalmente, através dos dados disponibilizados na Tabela 3, pode-se interpretar que os resultados constituem uma amostragem-piloto e indicam a necessidade de uma intensidade amostral de 162 parcelas para atingir $10 \%$ de erro admissível para cálculo do volume de madeira.

Tabela 3-Estatísticas da amostragem para determinação do volume de madeira, em que $\mathrm{n}^{*}=$ número ideal de parcelas e $p=0,05$. 'População" docomplexofernuginosoNectandra amostrada em 14 parcelas de 40 × $40 \mathrm{~m}$, na Floresta Nacional de Ibirama, SC

Table 3 - Sampling statistics to determine wood volume, where $n *$ is the ideal number of parcels and $p=0.05$. Population of Nectandraferruginous complex sampled in 14 parcels of $40 \times 40 \mathrm{~m}$, at the Ibirama National Forest, SC, Brazil

\begin{tabular}{lc}
\hline Estatística & Precisão da Amostragem \\
\hline Variância populacional & 1,26 \\
Erro-padrão da média do & 0,34 \\
volume $\left(\mathrm{m}^{3}\right)$ de madeira/ha & 112,96 \\
Coeficiente de variação $(\%)$ & 60,38 \\
Erro amostral para cálculo do & \\
volume de madeira (\%) & 162 \\
$\mathrm{n}^{*}$ para $10 \%$ de erro admissível & \\
\hline
\end{tabular}




\section{CONCLUSÃO}

Com base nos dados analisados do complexo ferruginoso Nectandra (CFN) para a condição de Floresta Ombrófila Densa da Região Sul do país, concluiu-se que:

- O CFN possui ampla distribuição pela área, o que constitui vantagem importante para o manejo.

- Há formação de um banco de plântulas distribuído numa curva exponencial negativa ("J" invertido), fator também favorável ao manejo. Ocorrem "gargalos" para o manejo na passagem da classe diamétrica de 8-16 para 16-24 cm e nas classes de altura entre 5 e $9 \mathrm{~m}$, representando, assim, fases que devem ser abastecidas no manejo.

- Para determinação do ciclo de corte, recomendase a determinação da dinâmica espacial e temporal do CFN. Além disso, estudos de autoecologia e análises econômicas são imprescindíveis à exequibilidade do manejo em regime de rendimento sustentável.

\section{AGRADECIMENTOS}

Ao ilustrador Boris Woloszyn (ESALQ-USP) e aos professores Etelvino Bechara (USP), pela revisão do texto; e Maurício dos Reis (UFSC) e Alfredo Fantini (UFSC), pela oportunidade de desenvolver este trabalho.

\section{REFERÊNCIAS}

ÂNGELO, H.; GUIMARÃES, D. P. Subsídios econômicos ao manejo florestal sustentável na região amazônica. Revista Árvore, v.25, n.3, p.353-360, 2001.

ANJOS, A. et al. Analise do efeito de um manejo em regime de rendimento sustentável sobre o padrão de distribuição espacial do palmiteiro (Euterpe edulis Martius), utilizando a função K de Ripley. Revista Árvore, v.22, n.2, p.215-225, 1998.

BRASIL. Ministério da Agricultura.Lei n. 9985, de 18 de julho de 2000. Sistema Nacional de Unidades de Conservação. Brasília, 2000. cap. 3, p. 16.

BOLIGON, A. A. et al. Aspectos fitossociológicos de um fragmento da floresta natural de Astronium balansae Engl., no município de Bossoroca, RS.

Ciência Rural, v.35, n.5, p.1075-1082, 2005.

CARVALHO, P. E. R. Espécies florestais brasileiras: recomendações silviculturais, potencialidades e uso da madeira. Colombo: Embrapa, 1994. 640p.
CASTRO, C. F. A. Gestão florestal no Brasil colônia. 2002. 199f. Tese (Doutorado em Desenvolvimento Sustentável) - Universidade de Brasília, Brasília, 2002.

CLEMENT, C. R.; HIGUCHI, N. A floresta amazônica e o futuro do Brasil. Ciência e Cultura, v.58, n.3, p.44-49, 2006.

DURigan, G. et al. Sementes e mudas de árvores tropicais. São Paulo: Páginas e Letras Editoras Gráficas, 1997. 65p.

GAMA, J. R. V.; BENTES-GAMA, M. M.; SCOLFORO, J. R. S. Manejo sustentado para floresta de várzea na Amazônia Oriental. Revista Árvore, v.29, n.5, p.719-729, 2005.

HEINSDIJK, D.; BASTOS, A. M. Inventários florestais na Amazônia. Boletim do Serviço Florestal, v.6, p.1-100, 1963.

HERING, K. G. Natural Forest management in the Atlantic Coastal Rain Forest of Brazil. Plant Research and Development, v.40, n.1, p.7-23, 1994.

\section{KLEIN, R. M. Flora Ilustrada}

Catarinense: Meliáceas. Itajaí: Herbário Barbosa Rodrigues, 1984. 138p.

KLEIN, R. M. et al. Vegetação. In: GOVERNO DO ESTADO DE SANTA CATARINA (Ed.). Atlas de Santa Catarina. Rio de Janeiro: 1986. p. 35-36.

KREBS, C. J. Ecological methodology. New York: Harper \& Row, 1989. 654p.

MACEDO, A. C.; KAGEYAMA, P. Y.; COSTA, L. G. S. Revegetação: matas ciliares e de proteção ambiental. São Paulo: Fundação Florestal, 1993. 24 p.

MORISITA, M. Estimation of population density by spacing methods. Memoirs of the Faculty Science, Kyushu University, Serie (E) Biology, v.1, p.187-197, 1954.

MUNIZ, G. I. B.; MARCHIORI, J. N. C. Anatomia da madeira de três lauráceas da Floresta Estacional de Misiones, Argentina. Revista Ciência e Natura, v.21, p.77-96, 1999.

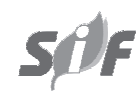

R. Árvore, Viçosa-MG, v.33, n.1, p.125-132, 2009 
PEDRALLI, G. Flora Ilustrada

Catarinense: Lauráceas 6. Nectandra. Itajaí: Herbário Barbosa Rodrigues, 1987. 93p.

PEDRALLI, G. Uma análise das observações de Rohwer sobre Lauráceas 6, Nectandra da Flora Ilustrada Catarinense. Sellowia, n.45-48, p.109-114, 1996.

REIS, A. Dispersão de sementes de Euterpe edulis Martius - (Palmae) em uma Floresta Ombrófila Densa Montana da Encosta Atlântica em Blumenau, SC. 1995. 154f. Tese (Doutorado em Biologia Vegetal) - Universidade de Campinas, Campinas, 1995.

REIS, M. S. et al. Management and conservation of natural populations in Atlantic Rain Forest: the case study of palm heart (Euterpe edulis Martius). Biotropica, v.32, n.4B, p.894-902, 2000.

REITZ, R.; KLEIN, R. M.; REIS, A. Projeto Madeira de Santa Catarina. Itajaí: Herbário Barbosa Rodrigues, 1978. 320p.

REITZ, R.; KLEIN, R. M.; REIS A. Projeto Madeira do Rio Grande do Sul. Sellowia, n.34-35, p. 1-525, 1983.

R. Árvore, Viçosa-MG, v.33, n.1, p.125-132, 2009
ROHWER. J. G. Notes on "Flora Ilustrada Catarinense, Lauráceas 6, Nectandra”. Sellowia, n.42-44, p.35-41, 1992.

ROHWER. J. G. Lauraceae: Nectandra. Flora Neotropica, v.60, p.1-332, 1993.

SALAZAR FILHO, H. O. et al. Floresta Nacional de Ibirama. [online] Disponível em:<http:// www.ibama.gov.br/ flonaibirama/ > Acessado em: 07/04/2008.

SANTA CATARina (Estado). Atlas de Santa Catarina. Rio de Janeiro: Governo do Estado de Santa Catarina, 1986. 173p.

TONINI, H.; FINGER, C. A. G.; SCHNEIDER, P. R. O crescimento da Nectandra megapotamica Mez., em floresta nativa na depressão central do Estado do Rio Grande do Sul. Ciência Rural, v.33, n.1, p.85-90, 2003.

VERÍSSIMO, A. et al. Impactos da atividade madeireira e perspectivas para o manejo sustentável da floresta numa velha fronteira da Amazônia: o caso Paragominas. In: BARROS, A.C.; VERISSIMO, A. (Eds.) A expansão da atividade madeireira na Amazônia: impactos e perspectivas para o desenvolvimento do setor florestal no Pará. Belém: IMAZON, 1996. p.47-73. 